\title{
Does the Welfare State Destroy the Family? Evidence from OECD Member Countries*
}

\author{
MaRTin HALLA \\ MARIO LACKNER \\ JOHANN SCHARLER \\ University of Innsbruck \& IZA \\ University of Linz \\ University of Innsbruck
}

Forthcoming in Scandinavian Journal of Economics

November 6, 2014

(First version: February 7, 2013)

\begin{abstract}
We study the effect of the size of the welfare state on demographic trends in OECD member countries. Exploiting exogenous variation in public social spending, due to varying degrees of political fractionalization (i.e. the number of relevant parties involved in the legislative process), we show that an expansion in the welfare state increases the fertility, marriage, and divorce rates with a quantitatively stronger effect on the marriage rate. We conclude that the welfare state supports family formation in the aggregate. Further, we find that the welfare state decouples marriage and fertility, and therefore, alters the organization of the average family.
\end{abstract}

JEL Classification: J12, J13, J18, D1, D62, H31, H53.

Keywords: Marriage, divorce, fertility, welfare state, risk sharing.

${ }^{*}$ Corresponding author: Martin Halla, University of Innsbruck, Department of Public Finance, Universitätsstrae 15, 6020 Innsbruck, Austria, ; ph.: +43(0)5125077154; email: martin.halla@uibk.ac.at. For helpful discussions and comments, we would like to thank two anonymous referees and the Editor Peter Fredriksson. The paper has also benefited from comments and discussions with Anders Björklund, Henriette Engelhardt-Woelfler, Alexia Fürnkranz-Prskawetz, Andrea Weber, Rudolf Winter-Ebmer, and the participants of the Labor Economics Workshop of the University of Padova and the University of Linz in Brixen (Italy), the 2011 Annual Meeting of the Austrian Economic Association in Graz (Austria), the 2011 Annual Conference of the European Society for Population Economics in Hangzhou (China), the 2011 Annual Congress of the European Economic Association in Oslo (Norway), and the 2011 Annual Conference of the European Association of Labour Economists in Paphos (Cyprus). The usual disclaimer applies. This research was funded by the Austrian Science Fund (FWF) National Research Network S103, The Austrian Center for Labor Economics, and the Analysis of the Welfare State. A previous version of this paper was circulated under the title "Welfare State and Family Behavior: Evidence from OECD Member Countries." 


\section{Introduction}

Family and kinship traditionally provided services such as care for the young and the elderly and provided insurance against unforeseen events such as illness and unemployment. Nowadays, governments in industrialized countries provide or at least subsidize these services, for instance, through public health and unemployment insurance. Thus, the role of the family may have become less important in this respect (Anderberg, 2007), and the incentives to form a family may have decreased along with the introduction of comprehensive welfare state arrangements. Nevertheless, the implementation of welfare state arrangements may incorporate (implicit or explicit) subsidies of certain family arrangements. If, for instance, welfare state regulations promote marriage and fertility, then the welfare state may also exert a crowding-in effect on families. Consequently, the overall effect is less clear.

Does the welfare state destroy or support the family? We study this issue by examining OECD member countries in the period from 1980 until 2007. Thus, in contrast to the existing literature, which examines specific welfare arrangements and reforms, we study the impact of welfare state arrangements on an aggregated level. To measure the extent of the welfare state, we mainly use public social spending as a percentage of GDP; but also more specific measurements such as public social spending on the family. Thus, we evaluate the effect of the average implementation of the welfare state in the sample of OECD member countries in the given time period. Demographic trends of family outcomes are captured by marriage, divorce, and fertility rates.

To obtain exogenous variation in the size of the welfare state, we turn to the literature on the political economy of public spending. This literature stresses the importance of political fractionalization for the level of public spending. ${ }^{1}$ We exploit varying degrees of political fractionalization - in particular, the number of relevant parties involved in the legislative process - as an instrumental variable. Our first stage estimations show a highly significant effect of within-country variation in political fractionalization on public (social) spending. The identifying assumption of our instrumental variable strategy is that political fractionalization in the parliament affects family behavior only through the channel of public social spending. While this assumption is not testable, there are few determinants of family behavior that are reasonably correlated with political fractionalization. We discuss a number of potential mediating links (such as government's ideology or polarization, immigration, and taxation of families) and show that our estimated effects

\footnotetext{
${ }^{1}$ As we will discuss in detail below, the link between fractionalization and public spending can be derived from different political economy theories of public finance. While the so-called common pool theory holds that highly fractionalized systems are generally prone to increase spending, and, thus, lead to an expansion of the welfare state, Primo and Snyder (2008), argue that fractionalization may lead to lower spending. Intuitively, the benefits of smaller and cheaper projects can be easier to internalize by specific groups, leading to lower overall spending. For empirical evidence on the role of fractionalization, see, e. g. Volkerink and de Haan (2001).
} 
are very robust to the inclusion of these potential confounders. We hope that this discussion convinces the critical reader that using political fractionalization as an instrument for public social spending is a useful identification strategy in our context.

Our results indicate that a larger welfare state increases the turnover in the marriage market by increasing both marriage and divorce rates. Since the effect on marriage is stronger than that on divorce, an increase in the size of the welfare state increases the stock of married individuals. Further, we observe an increase in the fertility rate, which is particularly pronounced for non-marital fertility (as compared to marital fertility). Hence, while the welfare state supports the formation of families, it crowds-out the traditional organization of the family by increasing the divorce rate and the number of children born out of wedlock. All the estimated effects are highly statistically significant and their quantitative importance increases when we use a narrower measurement of the welfare state.

Three guideposts can be used to put this analysis in the context of existing literature. First, we add to the literature that studies the consequences of the welfare state in a general sense (Castles et al., 2010). Second, we add to the literature on demographic trends (Stevenson and Wolfers, 2007). ${ }^{2}$ With the exception of the out-of-wedlock ratio, comparably little attention has been paid to the influence of the welfare state on demographic outcomes. ${ }^{3}$ In the public debate, the dominant view is that the welfare state has to adjust to changing demographic patterns (as for instance, in the case of an aging society with extensive pensions systems). Our finding points to the reversed link, where the welfare state has the capacity to shape demographic outcomes. Finally, we provide empirical support for Gary S. Becker's claim that the organization of the family changes as the state supplements or replaces traditional family functions. In this regard, our empirical evidence complements the large literature examining the effects of specific U.S. welfare arrangements on family outcomes at less aggregated levels. ${ }^{4}$

Typically, scholars use variations in welfare benefit levels across time and states to identify the effects on family outcomes. By and large, micro analyses confirm theoretical expectations. Moffitt (1997) concludes that many existing studies find a negative effect of public transfers on marriage, and a positive effect on fertility. However, the estimated ef-

\footnotetext{
${ }^{2}$ Economic scholars have studied the role of the economic independence of women (Isen and Stevenson, 2011), access to abortion and oral contraception (Akerlof, Yellen and Katz, 1996; Goldin and Katz, 2000, 2002), changes in divorce law (Wolfers, 2006; Rasul, 2006; Matouschek and Rasul, 2008), and reforms of custody law (Halla, 2013).

${ }^{3}$ A notable exception is Björklund (2006) who identifies a positive effect of the Swedish family policy on the overall fertility level.

${ }^{4}$ Earlier papers evaluate the effect of Aid to Families with Dependent Children (AFDC) and more recent papers look at Temporary Assistance for Needy Families. In the case of AFDC-where the disposable income of recipients increases with children and decreases with marriage - one expects a decrease in marriage, an increase in divorce, and an increase in fertility, especially out of wedlock (Becker, 1993). TANF replaced AFDC (in 1996) and reversed some of the incentives of welfare arrangements. In fact, the major stated goals of this legislation included reducing out-of-wedlock births and increasing marriage.
} 
fects are generally small, sensitive to alternative econometric specifications, and a sizable minority of the papers find no effects at all. ${ }^{5}$ A possible explanation for the conflicting empirical evidence is a lack of econometric identification. Moffitt (1998) argues that many papers potentially suffer from endogeneity bias resulting from the use of endogenous variables measuring welfare benefits, and from control variables that are themselves outcome variables. ${ }^{6}$

While these micro-level analyses of specific welfare state arrangements are better suited for policy advise, we are able - based on aggregate outcomes and a focus on the welfare state in a broader sense - to demonstrate the effects on the family at a more aggregated level. In other words, we show that the welfare state (resulting from real-world political equilibria in OECD member states over the last decades) has indeed influenced aggregate demographic outcomes in a non negligible way. ${ }^{7}$

The remainder of the paper is structured as follows. The next section provides a theoretical discussion of the effects of the welfare state on family behavior. Following that, we describe our empirical strategy and the data. Then, we present the results and a number of robustness checks. The final section summarizes and concludes the paper. All data sources are described in the Data Appendix. A Web Appendix includes additional estimation results.

\section{Theoretical Considerations}

Typical real-world welfare state arrangements incorporate explicit subsidies for certain family arrangements. Besides explicit marriage-promoting polices (Gardiner et al., 2002; Brotherson and Duncan, 2004), many transfer programs and tax codes include implicit incentives to adjust marital status. In other words, the (welfare) state may directly influence the utility of being married versus being single, by either subsidizing or excising such statuses. Similarly, the welfare state may exert a direct influence on fertility by providing subsidies that at least partly compensate the costs of child care by providing, for instance, subsidized health care for children and education (Cigno, 1986). We refer to these effects of the welfare state as the direct effects, since a change in either marital status or fertility directly results in a change in disposable income that varies across different welfare state arrangements. If the welfare state predominately subsidizes marriage, then we expect the direct effect to result in an increase in marriage and a decrease in divorce, everything else

\footnotetext{
${ }^{5}$ For a survey of this literature, see Moffitt (1992); Murray (1993); Moffitt (1998); Blank (2002); Grogger and Karoly (2005). While most of the literature is based on US data, González (2005) and González (2007) use cross country survey data.

${ }^{6}$ Among more recent papers, there exist a handful of random assignment studies (see, for instance, $\mathrm{Hu}$, 2003). Another related strand of literature focuses on the effects of tax law on the incidence of marriage (Alm, Dickert-Conlin and Whittington, 1999) and divorce.

${ }^{7}$ As we will show in more detail below, the political equilibria is quite stable across countries and over time and thus each data points reflects a very comparable structured welfare state.
} 
equal. If, in contrast, welfare state arrangements are dominated by marriage-penalizing regulations, we should observe a decrease in marriage and an increase in divorce. ${ }^{8}$ Concerning fertility, we expect that the welfare state exerts an unambiguously positive direct effect since welfare state arrangements reduce the cost of child care. The direct effect on the distribution of births in and out of wedlock is, however, unclear. It depends on whether certain benefits (such as child support) vary across different martial statuses.

In addition to these direct effects, the welfare state is also likely to exert indirect effects on family formation and dissolution by providing services that were traditionally provided by families. While these arrangements also alter the utility of being married versus being single, as well as the net benefits of having children, their effects do not necessarily lead to a change in disposable income directly. According to the seminal analysis of family formation and dissolution presented in Becker $(1973,1974)$ and Becker, Landes and Michael (1977), marriage is viewed as a voluntary partnership for joint production, joint consumption, and risk sharing. Joint production refers to the idea that by specializing in market and non-market work, spouses can exploit their relative comparative advantages to maximize joint output. Joint consumption of household public goods allows spouses to reduce expenditure (compared to singles) for a given level of utility. Risk sharing means that voluntary transfers between spouses help to smooth out fluctuations in individual income streams.

By providing services such as care for the young and the elderly, the welfare state reduces the need for intra-family specialization and for the production of household public goods, which, ultimately, changes the relative utility of being married. Similarly, the role of children as an investment, in the sense that they provide care for aging parents, has lost importance due to the development of public pension systems, implying less incentives for having children.

In addition to influencing the overall level of fertility, the welfare state may lead to a decoupling of marriage and child bearing. According to Becker, marriage is an arrangement that allows for efficient joint production, especially in the case of children. However, by providing child care services and financial support, the welfare state reduces the need to exploit the efficiency gains associated with marriage. Thus, the welfare state may alter the distribution of births in and out of wedlock.

The welfare state also provides insurance against unforeseen events, and thus competes with risk sharing provided within families. In the absence of functioning insurance markets (as in developing countries today, or in the developed world in the past), marriage,

\footnotetext{
${ }^{8}$ It seems practically impossible to categorize a country's welfare state as either having a marriagepromoting or a marriage-penalizing effect. The number of relevant regulations is very high. For instance, U.S. General Accounting Office (2004) has identified 1,138 U.S. federal statutory provisions - comprising such categories as social security, taxation, employment benefits, military service benefits, and veterans' benefits - in which marital status is a factor. It is unclear how to weigh different regulations, since their quantitative impact may vary across individuals and across time.
} 
or more generally the family and kinship, provides individuals with unique risk-sharing opportunities. Spouses with imperfectly correlated income streams can smooth their consumption over time by engaging in risk sharing through voluntary transfers. In the presence of a comprehensive welfare state that provides, or at least subsidizes, insurance, for example, against illness, unemployment, or unexpected longevity, the role of the family as an informal risk-sharing arrangement may become less important. These indirect effects associated with the welfare state lower the utility of being married relative to being single, and reduce the incentive to marry and stay married. Essentially, the welfare state may act as a substitute for the family, crowd-out its formation, and increase divorce. ${ }^{9}$

There are at least two additional channels through which the welfare state may influence the incidence of divorce, either through the matching function on the marriage market or through assortative mating. In either case, the idea that the welfare state subsidizes or penalizes marriage, either directly or indirectly, is also relevant. Consider first the influence on the matching function: suppose that the welfare state predominantly promotes marriage. Then the individuals' reservation match quality should go down and we should observe an increase in marriages. However, since the marginal marriages are less well matched, the likelihood of divorce also increases. If, in contrast, the welfare state imposes a marriage penalty, we should observe less marriages of better matched spouses, and a decrease in divorce rates.

Consider next the influence on assortative mating. Since the welfare state generally acts as a substitute for the family, considerations such as the ability to share risks among spouses, for instance, become less prevalent. Consequently, other matching criteria may gain more importance. As suggested by Coontz (2005), this may increase the importance of love and companionship as a basis for marriage, which may reduce the match quality if these alternative matching criteria are less stable. In fact, Hess (2004) models individuals on a marriage market who face a (potential) trade-off between partners who provide risksharing opportunities and others who fit better in terms of love. The model predicts that if love is permanent and risk-sharing opportunities diminish over time, then emotionally well-matched couples are less likely to divorce (compared to couples who married due to the hedging role of marriage). In contrast, if love is only temporary and risk-sharing opportunities remain persistent, then emotionally well-matched couples are more likely to divorce. The empirical evidence supports the second case; couples with a relatively high potential to share risks, that is spouses with negatively correlated incomes, are characterized by a significantly lower probability of divorce. ${ }^{10}$ In short, under the assumption that other matching criteria are temporary, we expect the quality of marriages to suffer when

\footnotetext{
${ }^{9}$ Note that the influence of these marriage-discouraging indirect effects of the welfare state may be mitigated by the fact that marriage has some features that makes it superior relative to the welfare state such as trust and information advantages (Kotlikoff and Spivak, 1981).

${ }^{10}$ This result is also in line with the observation by Becker (1993) that "modern societies have what may appear to be a paradoxical combination of many love-marriages and high rates of divorce."
} 
extensive welfare state arrangements exist.

To summarize, in a welfare state that penalizes marriages, the direct and indirect effects of an expansion in the welfare state work in the same direction. Thus, we unambiguously expect a lower incidence of marriage and a higher incidence of divorce. ${ }^{11}$ In contrast, in a welfare state setting that promotes marriage, the effect of an expansion is unclear. If the marriage-promoting direct effect dominates the indirect effect, the incidence of marriages should go up, and the number of divorces down. Whereas if the indirect effect is more important than the direct effect, we expect marriages to decrease and divorces to increase. In the latter case, the effect may be reinforced by a lower match quality of marginal marriages and less-stable assortative mating patterns.

The effect on fertility is also a priori ambiguous and depends on whether any direct subsidy effects are strong enough to compensate for the negative indirect effects, such as reduced incentives to have children being associated with extensive public pension systems. Finally, an extension in the welfare state should increase the incidence of out of wedlock births (marriage becomes less important for child care under an extensive welfare state), unless the welfare state has pronounced subsidies for marital birth.

In the next section we discuss how we aim to empirically identify the effect of the overall impact of the welfare state on aggregate demographic trends - reflecting the potential changes in family behavior discussed above.

\section{Empirical Strategy and Data}

Our discussion of a potential effect of the welfare state on aggregate demographic trends translates into a regression framework of the following type:

$$
D_{i, t}=\alpha_{r} \cdot \mathrm{WS}_{i, t}+\sum_{i} \beta_{i} \cdot \text { Country }_{i}+\sum_{t} \gamma_{t} \cdot \mathrm{Year}_{t}+\delta \cdot \mathbf{X}_{i, t}+\varepsilon_{i, t}
$$

where the dependent variable $D_{i, t}$ captures different demographic outcomes in country $i$ in year $t$ : either the incidence of marriage, divorce, or fertility. In the latter case, we distinguish between total fertility, marital fertility, and non-marital fertility. We also consider the ratio of children born out of wedlock as an additional outcome. The variable $\mathrm{WS}_{i, t}$ denotes a proxy for the extent of the welfare state, and $\beta_{i}$ and $\gamma_{t}$ denote country and year fixed-effects. In our baseline specification, we include a set of covariates $\mathbf{X}_{i, t}$, that comprise the sex-age distribution, the prevalent abortion law, the prevalent divorce law regime, the government's ideological orientation and the degree of polarization. The sexage distribution is captured by 24 variables measuring the share of the total population of sex $s$ in age group $a$ where $a$ is $0-14,15-19, \ldots, 60-64,65+$. The abortion law regime is

\footnotetext{
${ }^{11}$ Marginal marriages may have in this situation a lower divorce likelihood due to a comparable higher match quality.
} 
captured by a binary variable equal to one if abortion is legal (Bellido and Marcén, 2014), and zero otherwise. Regarding the divorce law, we distinguish between four regimes: (i) divorce is not possible at all, (ii) where only at-fault divorce is possible, (iii) where a no-fault divorce is available if both spouses agree; mutual consent divorce, and (iv) where a no-fault divorce is also available if only one spouse requests this; unilateral divorce. The coding is based on (González and Viitanen, 2009) and some national sources in the case of non-European countries. ${ }^{12}$ The control variables capturing the government's ideological orientation and the degree of polarization will be discuss below. In further specifications, we will expand our set of covariates to control for macroeconomic conditions, the share of immigrants, and the taxation of singles versus families. We calculate robust standard errors throughout. ${ }^{13}$

\subsection{Measuring Demographic Trends}

The standard in the literature to quantify the incidence of marriage and divorce seems to be crude marriage and divorce rates: the number of marriages (divorces, respectively) per 1,000 of the total population (e. g. Friedberg, 1998; Wolfers, 2006). While this approach is potentially problematic, since it does not properly consider the population "at risk," and may therefore hide some of the underlying variation of interest, data restrictions impede better approaches in most situations. In the case of marriage, the best measure would be the ratio of the number of marriages in a given year to the stock of the non-married adult population. ${ }^{14}$ In order to quantify the incidence of divorce, one would prefer to calculate the ratio of the number of divorces in a given year to the stock of the married population. Unfortunately, the stock of (non-)married people is not available for the majority of the country-years; exceptions are the years in which a population census was conducted. As a second-best solution, we calculate the marriage rate, $M_{i, t}$, and the divorce rate, $D_{i, t}$, based on the number of cases per 1,000 of the population between 15 and 64 years of age (henceforth adults).

To measure fertility, the literature discusses cohort and period indicators. Cohort indicators evaluate the birth rate of women born in a given year as they attain the

\footnotetext{
${ }^{12}$ The U.S. is the only country with within-country variation in divorce law (i.e. states switched to mutual consent divorce law and unilateral divorce law in different years). For the analysis, we impute the median-introduction years for the U.S.

${ }^{13}$ Due to the relatively small number of countries (we have 21 to 23 countries in our data set) we do not cluster the standard errors in our baseline specification. Since standard cluster adjustment relies on the assumption that the number of clusters approaches infinity, clustering may do more harm than good in the case of few clusters. Nevertheless, we report our main results based on two different alternatives of clustered standard errors in Section B.1 of the Web Appendix. In Table B.1 standard errors are clustered by country. Here, standard errors increase on average by a factor of two. However, these estimates have to be interpreted with extreme caution; due to the small number of clusters. In Table B.2 standard errors are clustered by country and electoral cycles. This results in 175 to 185 clusters, which coincide with the level at which our instrumental variable mainly varies. Here, standard errors increase on average only by a factor of 1.3 .

${ }^{14}$ Alternatively, one could also argue that married people are at risk to divorce and re-marry.
} 
end of their reproductive cycle, while period indicators asses the rate of birth to women of different ages in a given year, and implicitly assume that they behave according to hypothetical schedules of specific cohorts. Though cohort indicators are clearly more precise, the literature usually uses period indicators, since they are easily available and allow examination of recent changes (d'Addio and d'Ercole, 2005). We employ the most commonly used period indicator, the birth rate, which represents the absolute number of births (to either all, married, or unmarried mothers) per 1,000 women of child-bearing age. Information on births by mothers' marital status is available for comparably less country-years. See the Data Appendix for more information. ${ }^{15}$

\subsection{Measuring the Extent of the Welfare State}

To quantify the extent of the welfare state, we mainly use public social spending as a percentage of GDP. Averaged across OECD member countries, total public social spending increased from 17.6 percent of GDP in 1980 to 21.4 percent in 2007 (see Figure 1). Since the launch of the OECD Public Social Expenditure Database in 1980, this quantity is consistently measured for all OECD member countries and captures expenditure categories such as old age, health, incapacity-related benefits, family, unemployment, survivors, active labor market policies, and other (including housing). ${ }^{16}$ In each category, public social spending comprise cash benefits, direct "in-kind" provision of goods and services, and tax breaks with social purposes. ${ }^{17}$ On average, cash benefits account for 61.8 percent of total public social spending. Although, this relation has been relatively stable over time, a slight decrease can be observed since the early 1990s. For further information, see OECD (2007). Quantitatively the most important functional categories are old age, health, incapacity-related benefits, and family benefits. This composition is quite stable across countries and over time (see Section B.2 of the Web Appendix). That means that our estimates provide a stable and interpretable marginal effect of a typical change in the size of the welfare state.

\section{[ Insert Figure 1 about here]}

To check the robustness of our results, we use two alternative measures of the size of the welfare state, a wider measure and a narrower measure. First, we use the size of the

\footnotetext{
${ }^{15}$ For a large sub-sample, we have the total fertility rate (TFR) available. While TFR is a preferred measure, since it is not affected by the age distribution of the population, it does not allow us to distinguish between marital and non-marital fertility. For the overall fertility rate we find based on the TFR quantitatively very comparable results (see below).

${ }^{16}$ OECD also provides information on public social spending before 1980; however, there is (as Figure 1 shows) an obvious break in the series.

${ }^{17}$ Tax breaks intended to support married couples are not considered to serve a "social purpose", and are therefore not included in the calculations (regardless of whether or not such measures are part of the basic tax structure). Thus, the category "family" will capture only the effect of the welfare state and not the effect of the tax law (on family behavior).
} 
government sector as measured by total public spending as a percentage of GDP. This series is available since 1970 (see Figure 1). Given that the size of the government sector is clearly very broad and includes spending items that may be only remotely related to family behavior, one may expect a weaker effect. Second, we use public social spending on the family as a percentage of GDP. This series is available since 1980 (see Figure 1). This subcategory of total public social spending comprises welfare state arrangements directly related to families, such as child allowances and credits, child-care support, income support during leave, and sole parent payments. Public social spending on the family has increased (averaged across OECD member countries) from 1.7 percent of GDP in 1980 to 2.2 percent in 2007; this is equal to an increase of about 30 percent.

Note that although total public spending is available since 1970, we still focus on the data from 1980 to 2007 in our main analysis since this sample guarantees comparability of the estimation results across measures. ${ }^{18}$ In Section 4.3, we briefly report on the results based on the longer sample.

\subsection{Endogeneity of the Size of the Welfare State}

The size of the welfare state may be endogenous in equation (1) for at least two reasons. First, causality may run from existing or evolving family outcomes to the size of the welfare state. For instance, the welfare state may have expanded to compensate for declining marriage rates and provide services no longer provided within families. For instance, Edlund and Pande (2002); Edlund, Haider and Pande (2005) argue that the decline in marriage has increased the demand for redistribution by females (resulting in a political gender gap), which increased the size of the welfare state. In this case, changing family formation patterns causally affect the size of the welfare state. Second, there may have been changes in other observable or unobservable factors - such as changes in (sexspecific) economic opportunities, in the organization of the marriage market, or in social norms - affecting the incentive to form or dissolve a family that are also correlated with the extent of the welfare state.

It is hard to determine the sign of the potential bias, as it depends on the correlation between the welfare state and the confounding factor(s) after partialing out the covariates (such as country fixed effects). Consider, for instance, a temporary historical shock to fertility. If this shock results in a higher demand for welfare spending in the present, then there will be a negative covariance between the transformed key regressor (after

\footnotetext{
${ }^{18}$ Table B.3 in the Web Appendix shows the values of each of our measures of the welfare state in the first year for which we have an observation. We see that the initial size of the welfare state varies strongly across countries regardless of which proxy we use. Initial public social spending varies from 9.92 percent of GDP in Portugal to 27.16 percent in Sweden. Public spending on the family amounted to only 0.47 percent of GDP in Spain, whereas it was 3.09 percent in Sweden, in the first year. Public spending, the broadest category we consider, ranges from to 29.25 percent of GDP in Greece to 62.78 percent in Sweden.
} 
eliminating country fixed effects) and the transformed error term. This would gives rise to a downward bias in the estimated coefficient.

\subsection{Political Fractionalization as a Source of Exogenous Varia- tion}

To allow for a causal interpretation, we adopt an instrumental variable strategy to isolate exogenous variation in the size of the welfare state. We suggest to instrument $\mathrm{WS}_{i, t}$ in equation (1) by a measure of political fractionalization, which refers to the number of relevant parties involved in policy decisions. The choice of this instrumental variable is motivated by the political economy theories of public finance. According to the socalled common pool theory, highly fractionalized systems are prone to increase spending since individual groups do not fully internalize the costs (see e.g. Weingast, Shepsle and Johnsen, 1981; Velasco, 2000). The larger the number of parties involved - that is, the more fractionalized the system - the stronger is the incentive to over-spend. Note that the use of the terms fractionalization and fragmentation is not unambiguous in the literature. Although it usually refers to the number of parties participating in fiscal policy decision making, it is also used to describe the ideological coherence of groups involved in policy making (see Volkerink and de Haan, 2001).

Primo and Snyder (2008), in contrast, argue that fractionalization may lead to lower spending, especially with respect to total public spending. Intuitively, suppose that legislators have a choice of one large project that benefits all groups to some extent, or several small projects where each project benefits only an individual group. Even though the large and more expensive project might be more appropriate, individual groups may push for smaller and cheaper projects that allow them to internalize group-specific benefits to a greater extent. In this case, total public spending can be lower, albeit each group pushes for an inefficiently expensive project.

The empirical evidence is also mixed. A number of studies (see e.g. Roubini and Sachs, 1989,b; Persson and Tabellini, 2004, among others) find that more fragmented governments lead to higher spending and deficits. However, as pointed out by Acemoglu (2005), these results may be subject to a substantial endogeneity bias, which is typically not addressed in a proper way.

Different measurements for party fractionalization exist. We use an index proposed by Rae (1968) that focuses on the degree of legislative fractionalization of the party-system. In particular, the Rae-Index is defined as $1-\sum_{i=1}^{n} s_{i}^{2}$, where $s_{i}$ is the share of parliamentary seats for party $i$ and $n$ is the number of parties. This means that a higher value of the Rae-Index indicates a more fractionalized system. We find a very stable relationship between legislative fractionalization and public spending in our data. The cross-sectional correlation between the Rae-Index and the level of public spending is positive (see the 
upper panel in Figure 2). Hence, it appears that a more fragmented legislative is associated with higher public spending. This relation also holds in a regression framework (with a large set of covariates). ${ }^{19}$ However, if we augment the regression equation with country fixed-effects - which account for unobserved time-invariant heterogeneity - the estimated coefficient is still highly significant, albeit with a negative sign (see the lower panel in Figure 2). Here, a one standard deviation increase in the Rae-Index decreases public spending by 0.4 standard deviations. Importantly, the same patterns are observable for public social spending, which is our main proxy for the size of the welfare state, as well as for public social spending on the family. Here the beta coefficients change due to the inclusion of country fixed-effects from 0.5 to -0.3 , and from 0.4 to -0.1 , respectively. These results suggest that the degree of party fractionalization is correlated with unobserved country-specific time-invariant heterogeneity in a way that disregarding country fixed-effects can diametrically reverse results. Clearly, the model with country fixed-effects is superior, and we conclude that a higher degree of legislative fractionalization in the party system leads to lower public (social) spending in OECD member countries. While older empirical contributions put forward a positive relationship, relying on different data sets and estimation methods, our finding is consistent with the theoretical prediction of Primo and Snyder (2008).

\section{[Insert Figure 2 about here]}

Note, however, whether a higher degree of fractionalization increases or decreases public social spending does not affect the validity of our key identifying assumptions. We presume that the number of relevant political parties involved in the parliament is not correlated with unobserved factors determining family behavior. In other words, our measure of political fractionalization must affect family behavior only through the channel of public social spending. Thus, political fractionalization can be excluded from the second-stage regression displayed in equation (1).

While this identifying assumption is not testable, it is instructive to discuss the source of variation in the degree of fractionalization. The Rae-Index changes either due to changes in popular support in elections, or due to institutional reforms that change the parliamentary representation of parties given their popular support. Empirically we cannot distinguish these two sources of variation, since such reforms typically become effective in election years. In our estimation sample about 98 percent of the changes in the RaeIndex take place in election years; i. e. the institutional reforms are essentially collinear with elections. The important question is, however, whether such institutional reforms or changes in popular support are correlated with unobserved factors determining family

\footnotetext{
${ }^{19}$ For instance, a regression of public spending on the Rae-Index and year fixed-effects suggests that an increase in the Rae-Index by one standard deviation increases public spending by 0.4 standard deviation. The estimated coefficient is significant at the 1-percent level.
} 
behavior. While we regard the former correlation as highly improbable, we think the latter relation requires an in-depth discussion. It appears conceivable that changes in the Rae-Index driven by changes in popular support coincide with changes in overall values and social norms, which could be directly related to our outcome variable. For instance, if changes in the fractionalization tend to coincide with shifts from left to right-wing governments (or vice versa), then our instrumental variable may be correlated with unobserved governments' characteristics that also affect family outcomes. In fact, we find some correlations between the Rae-Index and the government's ideological orientation. While the inclusion of respective control variables does not alter our estimation results, we include the share of cabinet posts held by left-wing, center, and right-wing parties (each weighted by days) as control variables in our baseline specification; where share of cabinet posts held by right-wing parties (and independents) serves as base group. Equivalently, one might speculate about a link between polarization within the government and family behavior. We use a three-valued indicator to measure polarization in the government in our baseline specification. ${ }^{20}$ Again, controlling for polarization does not change our results. Another mediating link (i. e., variable that is potentially correlated with political fractionalization and family behavior) we can think of is immigration. For whatever reasons, more (or less) fractionalized governments may have a different immigration policies; which in turn might affect family behavior. Again, our results are robust to the inclusion of the share of immigrants. Finally, one might be concerned about the potential influence of demographic variables on political outcomes. Alesina and Giuliano (2011) show, for instance, that family ties influence political participation. However, although the family and political outcomes may be interlinked in general, it is unclear how family ties affect fractionalization of the government.

Before we turn to the discussion of our estimation results it should be noted that based on our instrumental variable approach, we are able to measure the impact of marginal changes in the extent of the welfare state (due to variation in the political fractionalization) at the intensive margin. It is unclear whether a variation at the extensive margin (i.e., the introduction of a welfare state) has the same effect on the formation and dissolution of families.

\footnotetext{
${ }^{20} \mathrm{~A}$ government is least polarized (41.8 percent of our observations) if it consists only of either leftwing, center, or right-wing parties. It is most polarized if it consists of both left and right-wing parties (33.3 percent). Medium polarized governments are a mix of left-wing and center parties or right-wing and center parties (24.9 percent). We include binary indicators to capture these three levels.
} 


\section{Estimation Results}

\subsection{Main Results}

Table 1 presents the main results of this paper, where we use public social spending to capture the size of the welfare state. ${ }^{21}$ To facilitate an easier interpretation of the quantitative importance of our estimation results, we provide in the upper panel besides the coefficients and the standard errors also semi-elasticities (using the unweighted mean as the base) and standardized (beta) coefficients. For comparison, we also report corresponding OLS estimates. The lower panel summarizes our first stage results. The Rae-Index is highly significantly negative in all specifications and the Kleibergen-Paap F-statistic indicates that the Rae-Index is not a weak instrument.

\section{[Insert Table 1 about here]}

The first three columns show that an expansion in the welfare state increases the incidence of marriage, divorce, and fertility. The extent of the welfare state is not only a statistically significant but also a quantitatively important predictor of these rates. The estimates imply that an increase in public social spending by one percentage point of GDP increases the marriage rate by 2.4 percent, the divorce rate by 3.9 percent, and the fertility rate by 2.1 percent. This is equivalent to the beta coefficients of approximately $0.5,0.4$, and 0.5 , respectively. Interestingly, endogeneity seems to play a more important role in the case of marriage and fertility. Here, OLS and instrumental variable estimates are even of opposite signs, whereas in the case of divorce, both estimators provide the same qualitative conclusion. Comparing the point estimates shows that the OLS estimates are downward biased in the case of each outcome.

These results suggest that welfare state regulations contain a strong marriage-promoting component (direct effect) that overcompensates any crowding-out due to substitutability between the family and the welfare state (indirect effect). An equivalent relationship seems to hold between the welfare state and overall fertility. Thus, the welfare state clearly promotes the formation of families. However, at the same time, a larger welfare state also facilitates the dissolution of families. The positive effect on the incidence of divorce may result from different causal channels. First, a more pronounced welfare state may facilitate divorce by providing or subsidizing goods and services to divorced spouses that would be otherwise only available within marriage (e.g., risk sharing). Put differently, in the case of divorce, the indirect effect may dominate the direct effect. Second, marginal marriages - those which would have not been formed without the marriage-promoting

\footnotetext{
${ }^{21}$ We use the subset of 570 country-years with non-missing information on the marriage, divorce, and overall fertility rates in the first three columns. In the remaining three columns, we use the 538 countryyears with information on fertility rates by marital status.
} 
component of the welfare state - may have a lower match quality, which increases marital instability. Third, the welfare state may alter assortative mating patterns such that less stable marriages are formed. ${ }^{22}$

Given that our measurements of the incidence of marriage and divorce are both flow measurements, our results allow the interpretation that a large welfare state increases activity in the marriage market. This result is in line with the theoretical predication by Anderberg (2007). A larger welfare state seems to facilitate the transitions between different family status. This result seems plausible since such transitions are usually associated with high cost and uncertainty. Comparing the two estimated coefficients, we see that the flow into marriage (plus 210 marriages per 1,000 adults) is higher than the flow out of marriage (plus 118 divorces per 1,000 adults). Thus, the overall effect of an expansion of the welfare state on the stock of married people is positive. ${ }^{23}$

The result that countries characterized by extensive welfare states tend to have higher fertility rates is consistent with the interpretation that the welfare state increases the demand for children (crowding-in effect), for instance, by subsidizing children via benefits or tax deductions. ${ }^{24}$ This direct effect seems larger than any negative indirect effect. A more detailed investigation of fertility patterns shows that an expansion of the welfare state also alters the distribution of births in and out of wedlock. The fourth and fifth columns show that an expansion of the welfare state increases fertility rates among married mothers (1.6 percent) and non-married mothers (3.9 percent). Despite the fact that an expansion increases the incidence of marriage - and therefore, increases the population at risk for married fertility - we observe a comparably larger relative increase in out-ofwedlock births. This is also reflected in the final column, where we see that an increase in public social spending by one percentage point of GDP increases the share of children born out of wedlock by approximately 0.7 percentage points. This finding is consistent with the view that the welfare state creates incentives by providing higher support for single mothers (direct effect, as for instance in the case of AFDC), and with the idea that the welfare state acts as a substitute for a stable union (indirect effect).

\footnotetext{
${ }^{22}$ In principle, it is possible that the increased incidence of divorce drives some of the positive effect on the marriage rate (i.e., divorces increase the supply of potential partners in the marriage market). This could be tested with data on first (and further) marriages. However, this information is not available for the majority of country-years. Similarly, data on demographic outcomes by age or cohort would enable further tests; but these are hardly available.

${ }^{23} \mathrm{~A}$ more direct test of the effect of the welfare state on the stock of married population, would be to use the stock of married population as an outcome variable. However, due to limited data availability, such an analysis is not feasible for a large panel of countries. The stock of population by family status is usually only available for the census years.

${ }^{24}$ Table B.4 in the Web Appendix summarizes estimation results based on the TFR. We obtain the same qualitative results. A comparison of the respective beta coefficients shows that the effects are larger when using the TFR.
} 


\subsection{Alternative Measurements of the Welfare State}

While we rely on public social spending to measure the size of the welfare state in our main analysis, we find very comparable results for public social spending on the family (see Table 2) and public spending (see Table 3); both spending variables are measured as a percentage of GDP. Using public social spending on the family has the advantage that it is the most narrowly defined spending category and contains spending that is closely related to families. Given this close link to family formation and dissolution, we expect larger effects with this spending category. Nevertheless, relating public spending categories to family formation and family structure remains a complicated task. For instance, public expenditure on education is included in public spending, but not in public social spending (on the family). Since education spending is presumably an important determinant of family structure, we also look at public spending as a broader measure of the welfare state.

\section{[ Insert Tables 2 and 3 about here]}

We see from Tables 2 and 3 that the same qualitative conclusions emerge regardless of the proxy for the size of the welfare state. Using public social spending on the family, the magnitudes of the effect of the welfare state generally increase as beta coefficients roughly double. Note, that in the case of the martial fertility rate the standard errors increase and the effect is no longer significant at conventional levels. ${ }^{25}$ For public spending (the broadest category), based on a strong first-stage regression, all effects remain statistically significant and magnitudes tend to be somewhat smaller.

Finally, we also used public social spending net of the category 'old age' as an alternative measure of the size of the welfare state (see Table B.5 in the Web Appendix). The idea is that family formation and dissolution is mainly driven by younger couples, and should therefore not strongly (or, at least not directly) react to variation in spending on pensions and other social services for the elderly people. As expected, we find the same qualitative results, with generally larger, albeit less significant, quantitative effects as compared to the baseline specification. It has to be noted, however, that these results have to be interpreted with some caution as the Kleibergen-Paap F-statistics are only between six and seven.

\subsection{Sensitivity Analysis}

To check the robustness of our results, we ran a number of alternative specifications. The results are summarized in Figure 3, where the panels are organized by the different

\footnotetext{
${ }^{25}$ Relatedly, the Kleibergen-Paap F-statistics are generally only about eight.
} 
outcome variables. ${ }^{26}$ Each panel also shows the respective estimates from the baseline specifications.

\section{[ Insert Figure 3 about here]}

First, we use the first lag of public social spending instead of the contemporaneous value. We see that the effects on the marriage, divorce, and fertility rates are rather similar to our baseline specification. Second, we augment the specification with the real GDP growth rate as the overall-level economic activity may also have a potential impact on demographic outcomes (see, e.g., Hellerstein and Morrill, 2011). We obtain highly similar results. Third, we include the share of immigrants as an additional covariate. As discussed earlier, immigration is a potential confounding factor, since it may be correlated with fractionalization and demographic outcomes. We again obtain similar results. ${ }^{27}$ Fourth, we augment the baseline specification with controls for family related taxation. In particular, we include a measure of the average income tax rate for (i) a single with no child, and (ii) a married couple with two children. ${ }^{28}$ While explicitly controlling for taxation renders the effects insignificant for divorce and for the wedlock ratio, overall, our results remain robust.

We also examine the robustness of our results with respect to the sample chosen. First, we checked whether our results are driven by observations from countries with a certain electoral system. Therefore, we exclude all countries (about 23 percent of the sample) characterized by a majority voting system according to Blaise and Massicotte (1997). Our overall results, remain robust in these estimations (see Table B.6 in the Web Appendix). It is reassuring that our results are not strongly influenced by how popular vote is mapped into parliamentary representation.

Second, we examined longer sample periods since the data on public spending and public social spending are available since $1970 .{ }^{29}$ With the longer series, we obtain the same qualitative results for both measurements, although the effects are less precisely estimated (see Tables B.7 and B.8 in the Web Appendix). Quantitatively, we observe a small increase (across all outcomes) in the case of public social spending, while we see some comparably smaller effects for public spending. Finally, we account for the fact that the Rae-Index hardly varies in between elections by aggregating our data to election cycles, which results in about 180 observations. For all other variables we generate their

\footnotetext{
${ }^{26}$ For our two alternative measurements we performed the same set of alternative specifications. The Figures B.1 and B.2 in the Web Appendix show that also these results are qualitatively robust.

${ }^{27}$ The best available data on the number of foreign-born population we are aware of is included in the World Development Indicators Database provided by the World Bank. Since information is only available for every fifth year, we linearly interpolated the series to impute for missing years.

${ }^{28}$ These estimated average tax rates are taken from the OECD Taxing Wages Database, which presumes for the single, earnings of 67 percent of the average production worker wage, and for the married couple a principal earner with 100 percent and spouse with 33 percent of the average production worker wage. Some missing values have been imputed by linear interpolation.

${ }^{29} \mathrm{~A}$ caveat is that the public social spending series show a break in 1980 .
} 
within spell-mean. ${ }^{30}$ Table B.9 in the Web Appendix summarizes estimations based on this aggregated data equivalent to our baseline specifications. Despite the smaller sample, we observe again qualitatively very comparable results.

\section{Concluding Remarks}

Based on country-level data from OECD member countries from the past three decades, we conclude that a larger welfare state increases the turn-over in the marriage market. Since the effect on the incidence of marriage dominates the effect on divorce, the stock of married population increases. In addition, a larger welfare state also raises overall fertility. Thus, the welfare state supports the formation of families on an aggregated level. Yet, we find that the welfare state crowds-out the traditional organization of the family. The comparable stronger impact on non-marital fertility (compared to marital fertility) increases the share of children born out of wedlock.

This can be explained by the economic theory of the family, which also partly corroborates earlier results. It is consistent with the interpretation that the average welfare state in OECD member countries entails a positive direct effect that outweighs any negative indirect effect. The positive effect on divorce may result from a reduction in the (economic) cost of divorce by improvements in the post-divorce income situation (for average and marginal marriages). Put differently, the welfare state facilitates the formation and the dissolution of families. Whether these family transitions (triggered by the welfare state) are welfare enhancing or not, cannot be answered and remains an open question. However, since the welfare state reduces the cost of divorce, it seems plausible that surviving marriages are of better quality and exhibit higher marital satisfaction. Consequently, we would expect a lower level of extreme forms of marital distress in countries with a larger welfare state. $^{31}$

As in the case of every instrumental variable estimation, some uncertainty about the validity of the exclusion restriction may remain, since the identifying assumption is fundamentally untestable. While we hope that our discussion and the robustness checks have convinced the reader, we would propose for further research to use other sources of exogenous variation to test our hypotheses if any opportunity arises.

To which degree can our findings be generalized? A final caveat of instrumental variable estimations is that they provide only a local average treatment effect. In particular, our estimation captures the effect of a change in the extent of the welfare state due to a

\footnotetext{
${ }^{30}$ Since our measures of the size of the welfare state vary between elections, aggregation to election cycles entails a loss of information. The disaggregated analysis above exploits this in-between elections variation.

${ }^{31}$ Along similar lines, Stevenson and Wolfers (2007) argue that the introduction of unilateral divorce law, which can also be interpreted as a reduction in the cost of divorce, substantially reduced female suicide, domestic violence (for both men and women), and females murdered by their partners.
} 
varying degree of political fractionalization. While it is generally hard to assess the external validity, it seems attractive that our estimation relies on data from a broad range of OECD countries, comprising a variety of different programs which were implemented at different points in time. 


\section{References}

Acemoglu, D. (2005). Constitutions, Politics, and Economics: A Review Essay on Persson and Tabellini's The Economic Effects of Constitutions. Journal of Economic Literature, 43 (4), 1025-1048.

Akerlof, G. A., Yellen, J. L. and Katz, M. L. (1996). An Analysis of Out-ofWedlock Childbearing in the United States. Quarterly Journal of Economics, 111 (2), $277-317$.

Algan, Y. and Cahuc, P. (2009). Civic Virtue and Labor Market Institutions. American Economic Journal: Microeconomics, 1 (1), 111-145.

Alesina, A. and Giuliano, P. (2011). Family Ties and Political Participation. Journal of the European Economic Association, 9 (5), 817-837.

Alm, J., Dickert-Conlin, S. and Whittington, L. A. (1999). Policy Watch: The Marriage Penalty. Journal of Economic Perspectives, 13 (3), 193-204.

Anderberg, D. (2007). Marriage, Divorce and Reciprocity-based Cooperation. Scandinavian Journal of Economics, 109 (1), 25-47.

Becker, G. S. (1973). A Theory of Marriage: Part I. Journal of Political Economy, $81(4), 813-846$.

— (1974). A Theory of Marriage: Part II. Journal of Political Economy, 82 (2), 11-26.

- (1993). A Treatise on the Family, Enlarged Edition. Cambridge, MA: Harvard University Press.

—, Landes, E. M. and Michael, R. T. (1977). An Economic Analysis of Marital Instability. Journal of Political Economy, 85 (6), 1141-1187.

Bellido, Héctor and Marcén, Miriam (2014). Divorce Laws and Fertility. Labour Economics, 27 (1), 56-70.

BJörklund, A. (2006). Does Family Policy Affect Fertility? Journal of Population Economics, 19 (1), 3-24.

Blais, André and Massicotte, Louis (1997). Electoral Formulas: A Macroscopic Perspective. European Journal of Political Research, 32 (1), 107-129.

Blank, R. M. (2002). Evaluating Welfare Reform in the United States. Journal of Economic Literature, 40 (4), 1105-1166.

Brotherson, S. E. and Duncan, W. C. (2004). Rebinding the Ties That Bind: Government Efforts to Preserve and Promote Marriage. Family Relations, 53 (5), 459-468.

Castles, F. G., Leibfried, S., Lewis, J., Obinger, H. and Pierson, C. (eds.) (2010). The Oxford Handbook of the Welfare State. Oxford: Oxford University Press.

Cigno, A. (1986). Fertility and the Tax-Benefit System: A Reconsideration of the Theory of Family Taxation. Economic Journal, 96 (384), 1035-1051. 
Coontz, S. (2005). Marriage, A History: From Obedience to Intimacy, or How Love Conquered Marriage. New York: Viking.

D'Addio, A. C. and D'Ercole, M. M. (2005). Trends and Determinants of Fertility Rates in OECD Countries: The Role of Policies. OECD Social, Employment and Migration Working Paper 27, OECD, Paris.

Edlund, L., Haider, L. and Pande, R. (2005). Unmarried Parenthood and Redistributive Politics. Journal of the European Economic Association, 3 (1), 95-119.

— and Pande, R. (2002). Why Have Women Become Left-Wing? The Political Gender Gap and the Decline in Marriage. Quarterly Journal of Economics, 117 (3), 917-961.

FrIEDBerG, L. (1998). Did Unilateral Divorce Raise Divorce Rates? Evidence from Panel Data. American Economic Review, 88 (3), 608-627.

Gardiner, K. N., Fishman, M. E., Nikolov, P., Glosser, A. and Laud, S. (2002). State Policies to Promote Marriage - Final Report. Tech. rep., U.S. Department of Health and Human Services, Assistant Secretary for Planning and Evaluation, Washington, DC.

Goldin, C. and Katz, L. F. (2000). Career and Marriage in the Age of the Pill. American Economic Review, Papers 83 Proceedings, 90 (2), 461-465.

— and - (2002). The Power of the Pill: Oral Contraceptives and Women's Career and Marriage Decisions. Journal of Political Economy, 110 (4), 730-770.

Gonzalez, L. (2007). The Effect of Benefits on Single Motherhood in Europe. Labour Economics, 14 (3), 393-412.

Gonzalez, L. (2005). The Determinants of the Prevalence of Single Mothers: A CrossCountry Analysis. Institute for the Study of Labor (IZA) Discussion Paper 1677.

González, L. and Vittanen, T. (2009). The Effect of Divorce Laws on Divorce Rates in Europe. European Economic Review, 53 (2), 127-138.

Grogger, J. and Karoly, L. A. (2005). Welfare Reform: Effects of a Decade of Change. Cambridge, MA: Harvard University Press.

Halla, M. (2013). The Effect of Joint Custody on Family Outcomes. Journal of the European Economic Association, 11 (2), 278-315.

Hellerstein, K. H. (2011). Booms, Busts, and Divorce. The B.E. Journal of Economic Analysis $\&$ Policy: Contributions, 11 (1), Article 54.

Hess, G. D. and Sandler Morrill, M. (2011). Marriage and Consumption Insurance: What's Love Got to Do with It? Journal of Political Economy, 112 (2), 290-318.

Hu, W. (2003). Marriage and Economic Incentives Evidence from a Welfare Experiment. Journal of Human Resources, 38 (4), 942-963.

Isen, A. and Stevenson, B. (2011). Women's Education and Family Behavior: Trends in Marriage, Divorce and Fertility. In J. Shoven (ed.), Demography and the Economy, Chicago, IL: University of Chicago Press. 
Kleibergen, F. and PaAp, R. (2006). Generalized Reduced Rank Tests Using the Singular Value Decomposition. Journal of Econometrics, 133 (1), 97-126.

Kotlikoff, L. J. and Spivak, A. (1981). The Family as an Incomplete Annuities Market. Journal of Political Economy, 89 (2), 372-391.

LindBeck, A. and Nyberg, S. (2006). Raising Children to Work Hard: Altruism, Work Norms, and Social Insurance. Quarterly Journal of Economics, 121 (4), 1473-1503.

—, - and Weibull, J. W. (1999). Social Norms and Economic Incentives in the Welfare State. Quarterly Journal of Economics, 114 (1), 1-35.

Matouschek, N. and Rasul, I. (2008). The Economics of the Marriage Contract: Theories and Evidence. Journal of Law and Economics, 51 (1), 59-110.

Moffitt, R. A. (1992). Incentive Effects of the U.S. Welfare System: A Review. Journal of Economic Literature, 30 (1), 1-61.

- (1997). The Effect of Welfare on Marriage and Fertility: What Do We Know and What Do We Need to Know? Discussion Paper 1153, Institute for Research on Poverty Discussion, University of Wisconsin.

— (1998). The Effects of Welfare on Marriage and Fertility. In R. A. Moffitt (ed.), Welfare, the Family, and Reproductive Behavior, Washington, D.C.: National Research Council.

Murray, C. (1993). Welfare and the Family: The U.S. Experience. Journal of Labor Economics, 11 (1).

NechyBA, T. J. (2001). Social Approval, Values, and AFDC: A Reexamination of the Illegitimacy Debate. Journal of Political Economy, 109 (3), 637-672.

OECD (2007). The Social Expenditure Database: An Interpretive Guide SOCX 19802003. Interpretative Guide of SOCX, OECD, Paris.

- (2011). Public Social Spending. In OECD, Society at a Glance 2011: OECD Social Indicators, Paris: OECD Publishing.

Persson, T. and Tabellini, G. (2004). Constitutional Rules and Fiscal Policy Outcomes. American Economic Review, 94 (1), 25-45.

Pettersson-Lidbom, P. (2012). Does the Size of the Legislature Affect the Size of Government? Evidence from Two Natural Experiments. Journal of Public Economics, 96 (3), 269-278.

Primo, D. M. and Snyder, J. M. (2008). Distributive Politics and the Law of 1/n. Journal of Politics, 70, 477-186.

RaE, D. (1968). A Note on the Fractionalization of Some European Party Systems. Comparative Political Studies, 1 (3), 413-418.

RAsul, I. (2006). Marriage Markets and Divorce Laws. Journal of Law, Economics and Organization, 22 (1), 30-69. 
Roubini, N. and Sachs, J. D. (1989). Government Spending and Budget Deficits in the Industrial Countries. Economic Policy, 4 (8), 100-132.

— and - (1989b). Political and Economic Determinants of Budget Deficits in the Industrial Democracies. European Economic Review, 33 (5), 903-933.

Stevenson, B. and Wolfers, J. (2007). Bargaining in the Shadow of the Law: Divorce Laws and Family Distress. Quarterly Journal of Economics, 121 (1), 267-288.

Stevenson, B. and Wolfers, J. (2007). Marriage and Divorce: Changes and their Driving Forces. Journal of Economic Perspectives, 21 (2), 27-52.

U.S. General Accounting Office (2004). Defense of Marriage Act: Update to Prior Report. Tech. rep., Washington, DC.

Velasco, A. (2000). Debts and Deficits with Fragmented Fiscal Policymaking. Journal of Public Economics, 76 (1), 105-125.

Volkerink, B. and DE HaAn, J. (2001). Fragmented Government Effects on Fiscal Policy: New Evidence. Public Choice, 109 (3-4), 221-242.

Weingast, B. R., Shepsle, K. A. and Johnsen, C. (1981). The Political Economy of Benefits and Costs: A Neoclassical Approach to Distributive Politics. Journal of Political Economy, 89 (4), 642-664.

Wolfers, J. (2006). Did Unilateral Divorce Laws Raise Divorce Rates? A Reconciliation and New Results. American Economic Review, 96 (5), 1802-1820. 


\section{Tables and Figures}

Figure 1: Development of Public Spending Categories ${ }^{a}$

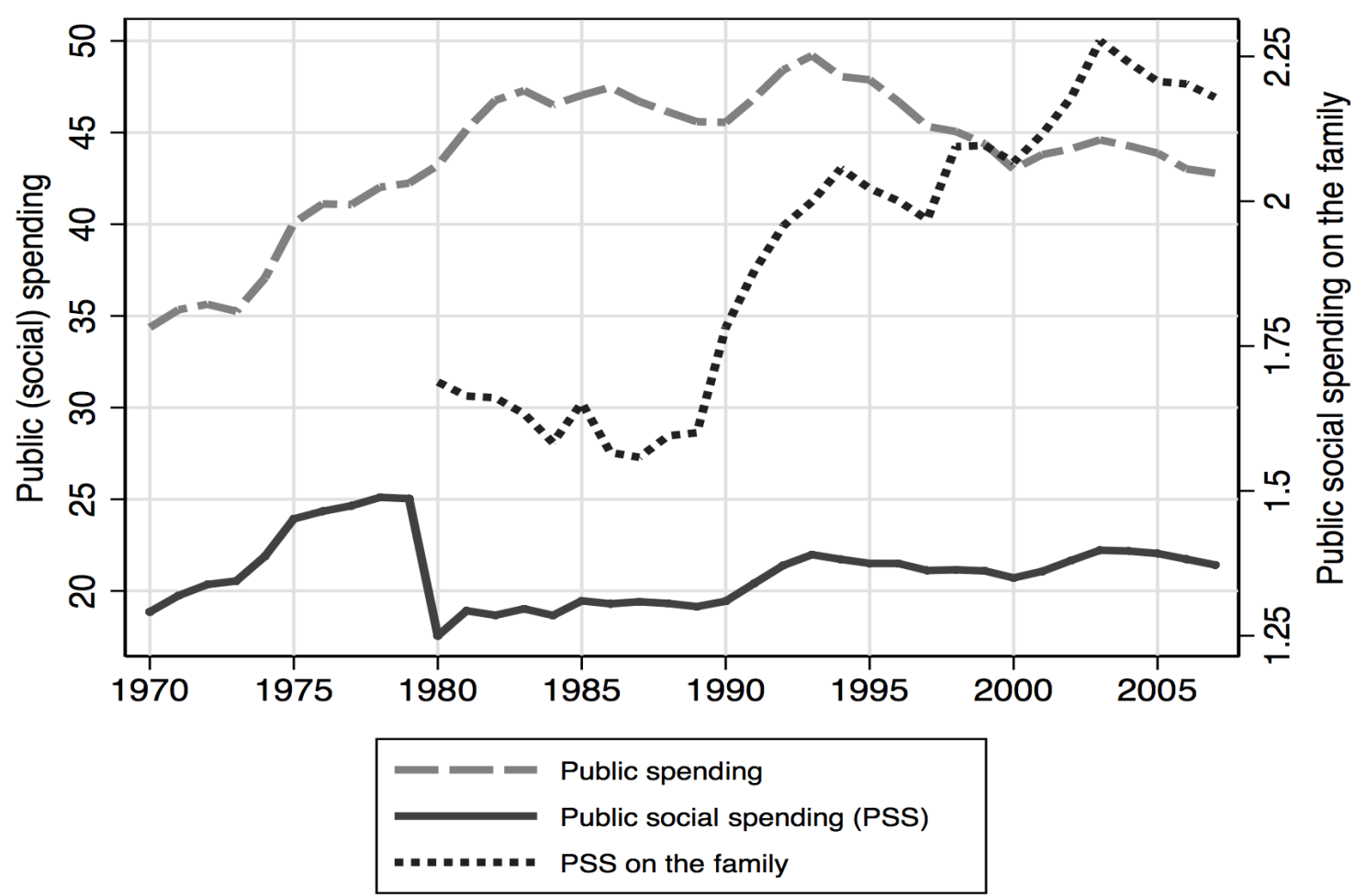

${ }^{a}$ This graph shows the development of pubic spending, public social spending, and public social spending on the family averaged across OECD member states from 1970 through 2007. Data on public social spending on the family is only available since 1980. All public spending categories are measured as percentage of GDP. Further details are provided in the Data Appendix. 
Figure 2: Public Spending and Legislative Fractionalization in OECD Member Countries (1980-2007) ${ }^{a}$
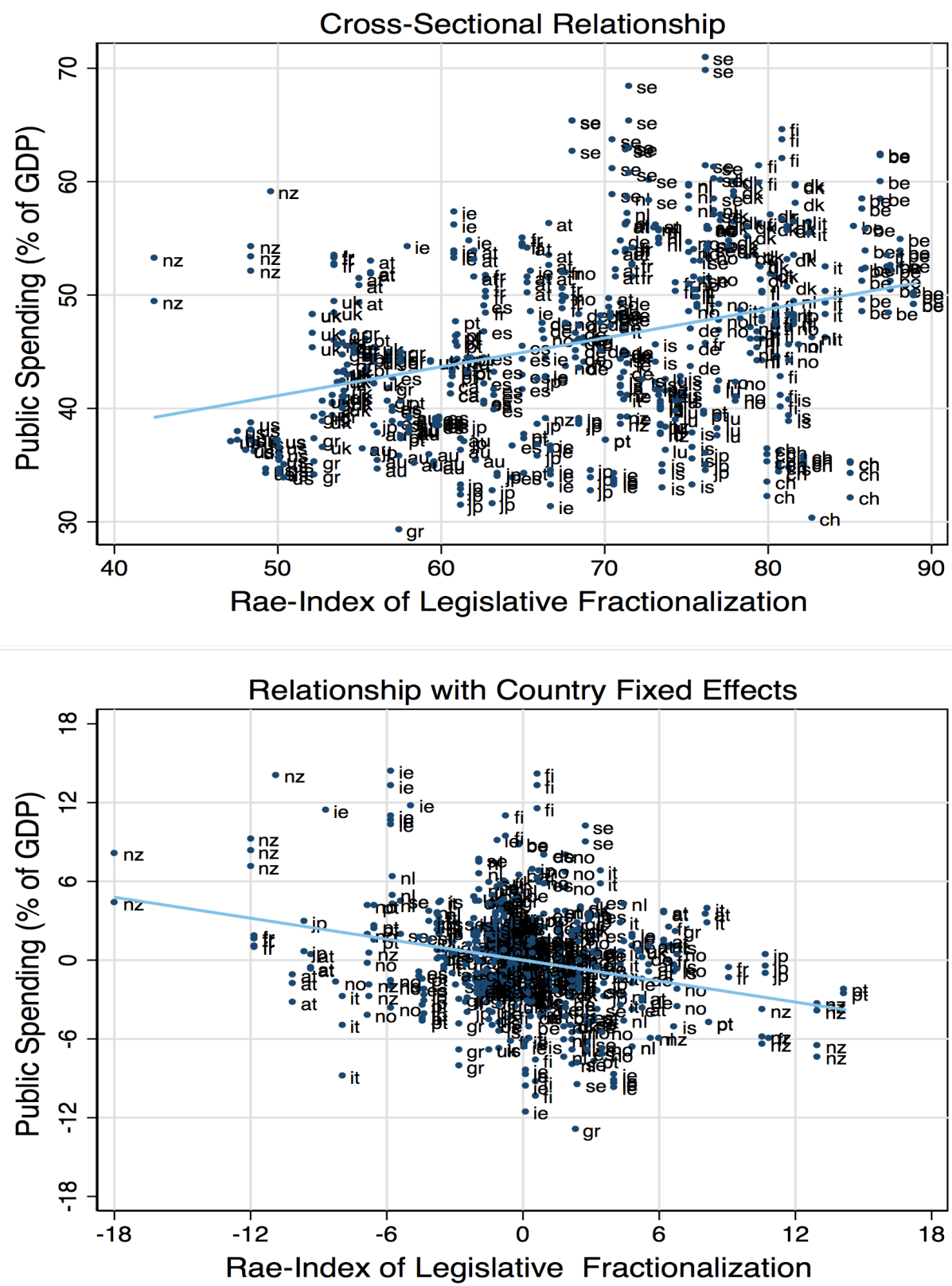

${ }^{a}$ These graphs show the relationship between public spending (measured as percentage of GDP) and the Rae-Index of legislative fractionalization of the party-system. A higher value of the Rae-Index indicates a more fragmented system. Further details are provided in the Data Appendix. The upper panel shows the simple cross-sectional relationship. The lower panel accounts (via demeaning) for country fixed effects 


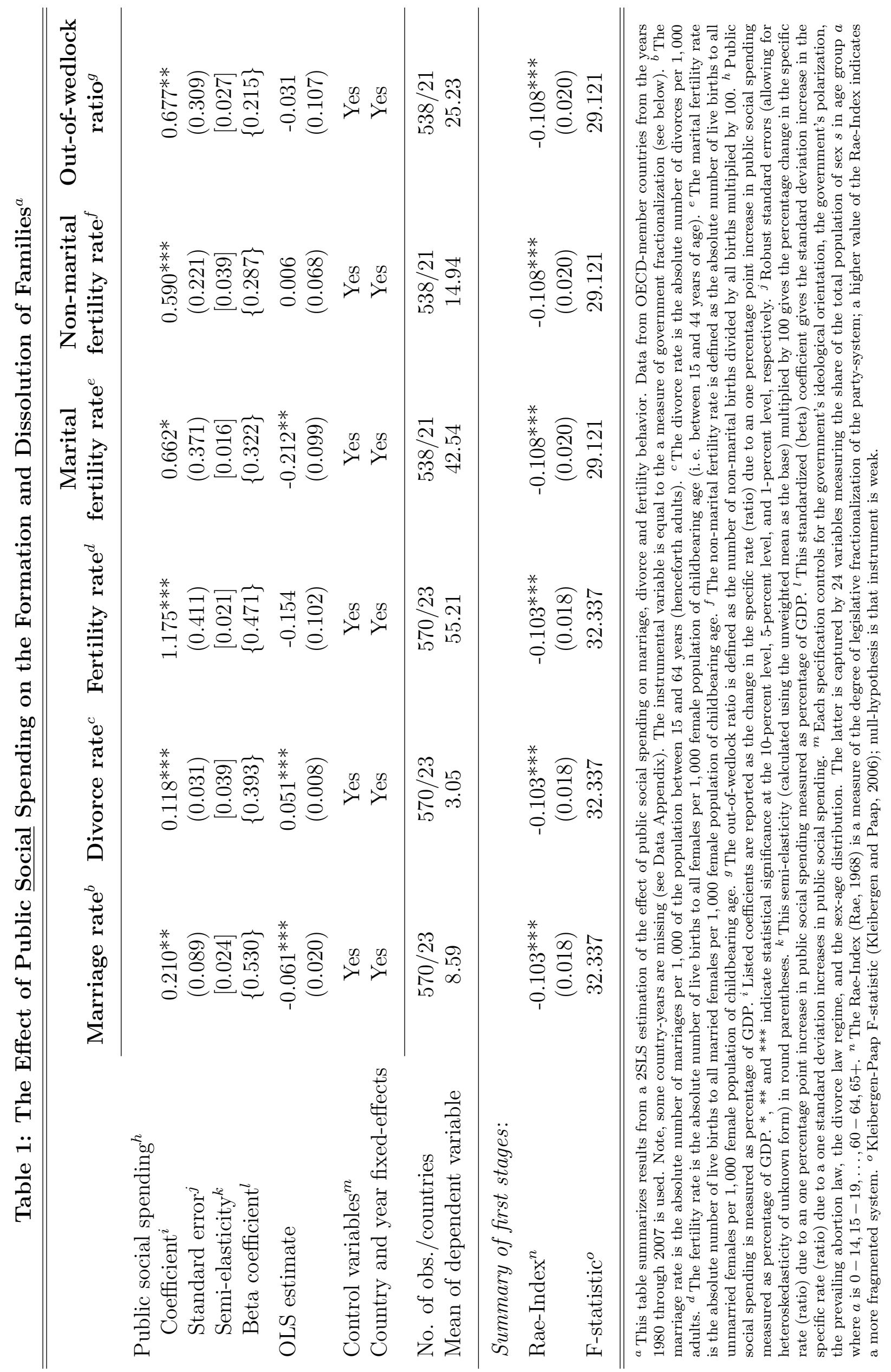




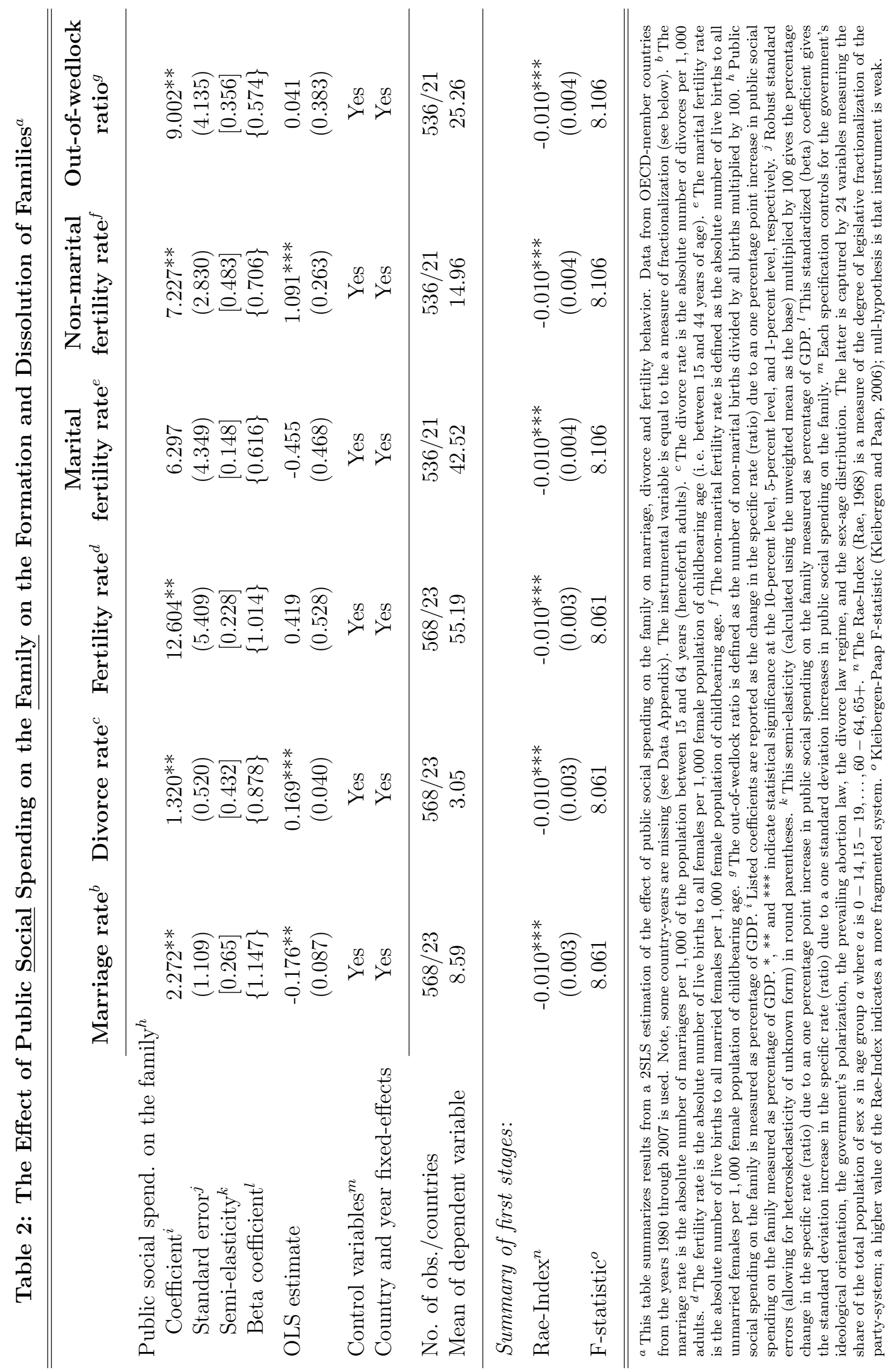




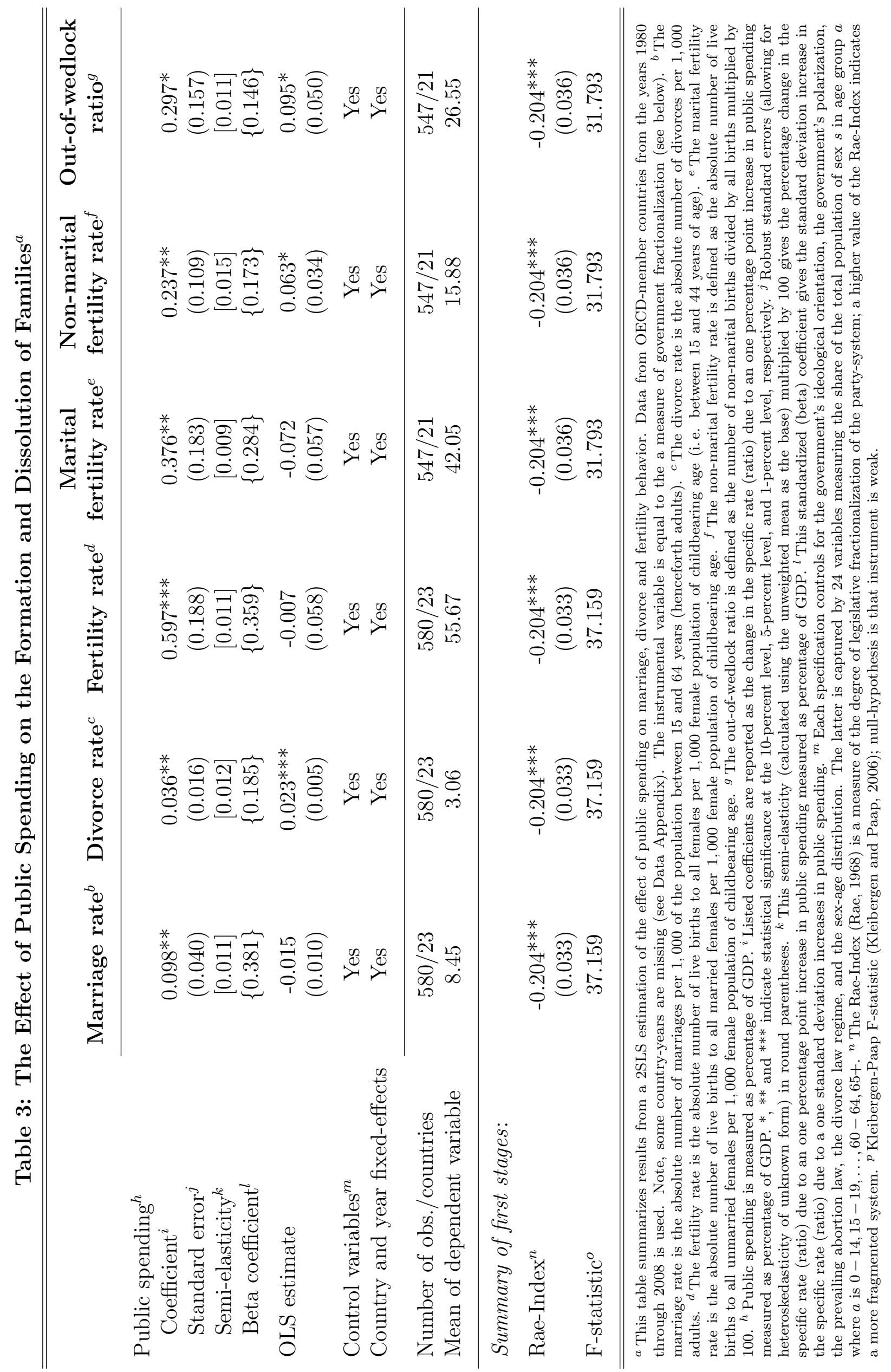




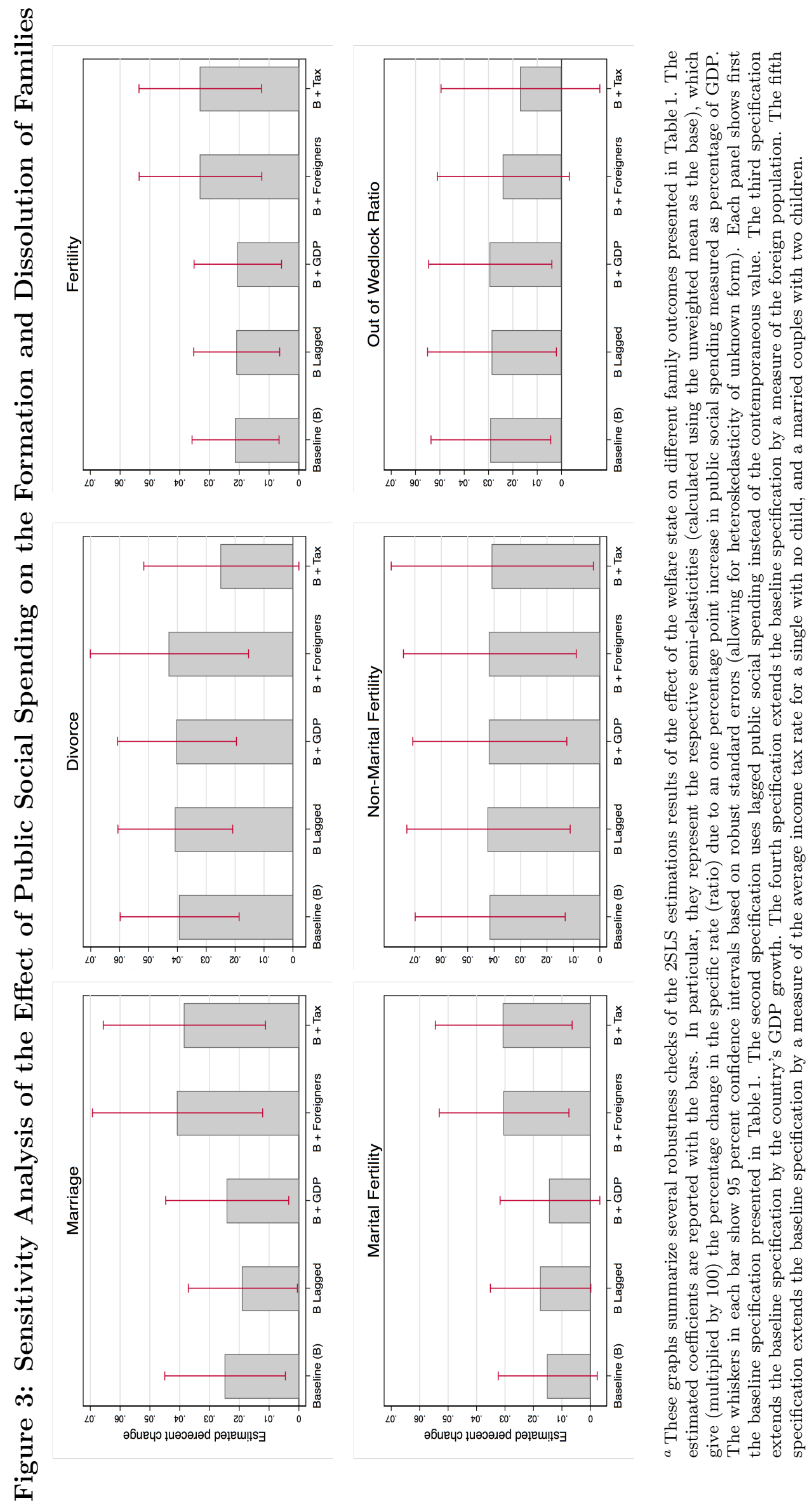

